\title{
Identification of fatigue crack propagation modes by means of roughness measurements
}

\author{
F.V. Antunes *, A. Ramalho, J.M. Ferreira \\ Department of Mechanical Engineering, University of Coimbra, Pólo II, Pinhal de Marrocos, 3030 Coimbra, Portugal \\ Received 5 January 2000; received in revised form 26 May 2000; accepted 30 May 2000
}

\begin{abstract}
This paper is a study of the applicability of fracture surface roughness measurements to identify the crack propagation mode in nickel base superalloys (transgranular, intergranular or mixed). The results obtained indicated that this technique can be used as an alternative or as a complement to standard fractography. The best roughness parameters for identifying the crack propagation mode are average roughness, mean roughness depth and mean height profile peak $\left(R_{\mathrm{a}}, R_{\mathrm{z}}\right.$ and $\left.R_{\mathrm{pm}}\right)$. Analysis of roughness spectra in terms of the frequency range showed that the amplitude values of the profiles with wavelengths identical to the grain size are significant when propagation is intergranular. The roughness measurements were used to study the influence of loading frequency and stress state on the fatigue crack propagation mode occurring in Inconel 718 tested at $600^{\circ} \mathrm{C}$. (C) 2000 Elsevier Science Ltd. All rights reserved.
\end{abstract}

Keywords: Crack propagation mode; Roughness parameters; High-temperature fatigue; Nickel base superalloys

\section{Introduction}

A crack propagation mode can be defined as a characteristic and reproducible fracture surface appearance (typically on the scale of micrometers or tens of micrometers) [1]. This appearance provides evidence of the fracture micromechanism, i.e. of the fracture process operating on the scale of microstructure. The microscopic technique normally used to identify the crack propagation mode is fractography. It permits the identification of individual features on the fracture surface, which provide clues about the fracture or fatigue process. Fractographic characterization may comprise nothing more than the assignment of a descriptive term to the fracture surface appearance.

Fracture surfaces have also been studied using roughness measurements. Thompson and colleagues [2,3] studied the roughness of fracture surfaces produced by microvoid coalescence with a view to relating the void shape with the mechanism of fracture. Casado et al. [4]

\footnotetext{
* Corresponding author. Tel.: +351-790-700; fax: +351-790-701.

E-mail address: fernando.ventura@mail.dem.uc.pt (F.V. Antunes).
}

studied a polymeric composite (thermoplastic polyamide reinforced with short glass fibers). They correlated the degree of damage, quantified by the surface roughness of the material, with the fatigue life. Roughness measurements have also been used to study crack closure induced by roughness. Ravichandran [5] proposed an equation relating grain size to $K_{\text {op }}$ (crack opening stress intensity factor); on the basis of that work, one can write the following expression:

$K_{\text {op }}=\alpha H^{\beta}$

where $a, \beta$ are experimental constants and $H$ is the standard deviation of the surface roughness measurements. Hamberg et al. [6] studied the relation between the microstructure, the fracture surface roughness and the crack closure level in steels. They found that the crack closure level increases with the roughness of the fracture surface according to:

$K_{\mathrm{cl}}=1.20 \bar{H}^{1 / 3}$

where the $K_{\mathrm{cl}}$ units are MPa $\mathrm{m}^{1 / 2}$ and $\bar{H}$ units (standard mean height) are $\mu \mathrm{m}$. In this analysis, $\bar{H}$ spanned values of a factor of approximately $30(1.6-42.9 \mu \mathrm{m})$. More than 400 material grains were transversed, which is enough for good average values to be obtained. 
Nickel base superalloys are a class of metallic materials that retain good properties at high temperatures, and they are therefore widely used under conditions of high-temperature fatigue [7]. The damage micromechanisms that can act at the crack tip and cause crack growth in nickel base superalloys are cyclic plastic deformation and oxidation. Depending on which damage micromechanism is primarily responsible for crack growth, three crack propagation regimes can be observed: cycle-dependent, time-dependent or mixed. In the cycle-dependent regime, cyclic plastic deformation is the main micromechanism of damage. Crack growth is transgranular and is proportional to the number of loading cycles. In the time-dependent regime, oxidation is responsible for crack growth [8]. Propagation is intergranular because the grain boundaries are preferential paths for diffusion and have a greater reactivity than the bulk material. Intergranular crack propagation makes the fracture surface rough. In the mixed mode regime, cycledependent and time-dependent micromechanisms exist simultaneously, and both contribute to crack growth. When one of the micromechanisms is delayed locally, the other acts. The relative percentage of each can be measured by the transgranular and intergranular regions existing on the fracture surface. Solomon [9] was the first to report the existence of these three regimes. They have been observed in other nickel base superalloys (AP1 [10], René 95 [11], Inconel 718 [12,13], Waspaloy [14] and Udimet 720 [15]).

The use of roughness measurements to identify the fatigue crack propagation mode in nickel base superalloys is therefore important. One problem with quantitative fractographic measurements is that there is no generally accepted definition of fracture surface roughness. Significant differences in the absolute value of surface roughness have been reported in the literature on alloys with virtually identical microstructures [6]. It is important to decide which surface features are relevant and which roughness parameters give the best information about the surface roughness characteristics for each case. The main objective of this paper is to study whether fracture surface roughness measurements can be used to identify the different crack propagation modes in nickel base superalloys (transgranular, intergranular or mixed). The appropriate roughness parameters are identified and a procedure for obtaining their typical values is established. Finally, this technique is used to study the influence of loading frequency and stress state on the fatigue crack propagation mode occurring in Inconel 718 , tested at $600^{\circ} \mathrm{C}$.

\section{Experimental procedure}

Fig. 1 presents the geometry of the Corner Crack (CC) specimens used in the high-temperature fatigue tests.
The material tested was Inconel 718, which is a nickel base superalloy (Ni, Cr, Fe, Nb, Mo, Ti, Al) [13,16]. The $\mathrm{CC}$ specimens were tested in a universal servo-hydraulic testing machine. The loading waveform was trapezoidal for loading frequencies, $f$, lower than $0.25 \mathrm{~Hz}$ (Fig. 2) and sinusoidal for $f>0.25 \mathrm{~Hz}$. The loading frequency varied from 0.0017 to $5 \mathrm{~Hz}$ and the stress ratio had the value $R=0.5$. A resistance furnace was used to obtain a constant specimen temperature of $600^{\circ} \mathrm{C}$ during the test.

The fracture surfaces were analyzed by scanning electron microscopy (SEM) to evaluate the main surface features, and roughness measurements were used to establish the crack propagation mode. Roughness measurements were taken using laser equipment (Mahr RM600 3D). The size of the spot is $1 \mu \mathrm{m}$ and the resolution of the equipment is $0.01 \mu \mathrm{m}$, giving better sensitivity than that achieved with stylus tip equipment. The geometry of the fracture surfaces was determined by analyzing the profiles from vertical sections perpendicular to the fracture surface and parallel to the main crack propagation direction. All measurements were carried out with an evaluation length of $1.5 \mathrm{~mm}$, a cut-off wavelength of $0.35 \mathrm{~mm}$ and a measurement speed of 20 $\mathrm{mm} / \mathrm{min}$. Since the grain size is about $15 \mu \mathrm{m}$, the number of grains transversed in the analysis was approximately 100. $\Delta K$ varies with crack length, but, given the small length used for roughness measurement evaluation, the influence on the roughness parameter values is expected to be small.

Several roughness parameters are used to assess the surface topography (Fig. 3) $[17,18] . R_{\mathrm{a}}$ is the roughness average, i.e. the arithmetic average of the absolute values of the roughness profile ordinates:

$R_{\mathrm{a}}=\frac{1}{l} \int_{0}^{l}|Z(x)| \mathrm{d} x$

where $Z(x)$ is the profile ordinates as shown on Fig. 3(a).

$R_{\mathrm{z}}$ is the mean roughness depth, i.e. the arithmetic mean value of the single roughness depths of five consecutive sampling lengths, see Fig. 3(b):

$R_{\mathrm{z}}=\frac{R_{z 1}+R_{z 2}+R_{z 3}+R_{z 4}+R_{z 5}}{5}$

$R_{\mathrm{pm}}$ is the mean height profile peak, i.e. the arithmetic mean value of the single highest profile peak measured for five consecutive sampling lengths, see Fig. 3(c):

$R_{\mathrm{pm}}=\frac{R_{p 1}+R_{p 2}+R_{p 3}+R_{p 4}+R_{p 5}}{5}$

$R_{\mathrm{sm}}$ is the mean width of the profile elements, i.e. the arithmetic mean value of the width of the roughness profile elements:

$R_{\mathrm{sm}}=\frac{1}{n} \sum_{i=1}^{n} S_{\mathrm{mi}}$ 


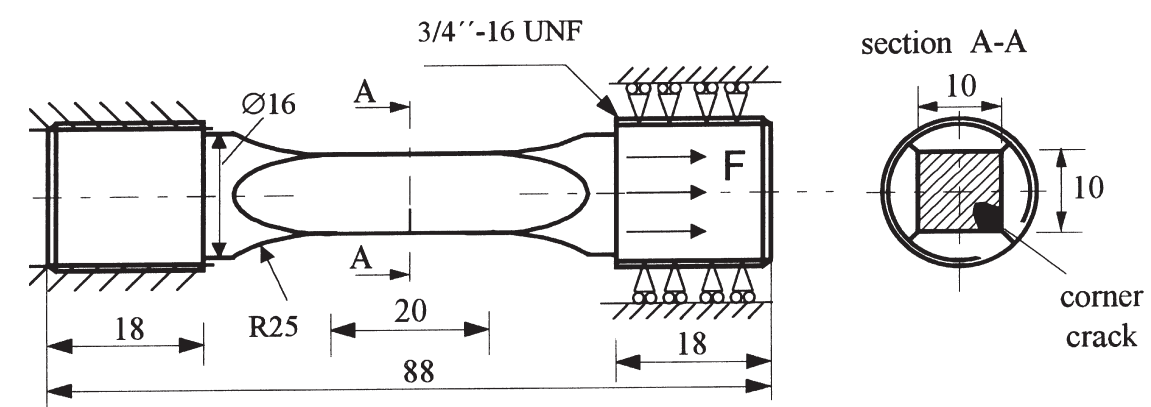

Fig. 1. Corner crack $(\mathrm{CC})$ specimen.

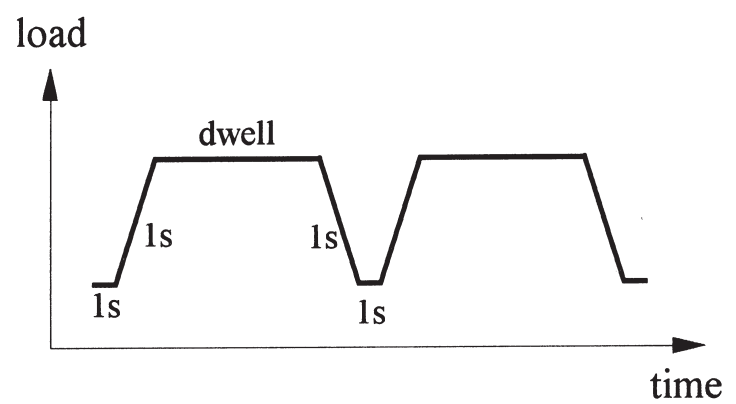

Fig. 2. Trapezoidal wave loading.

where $n$ is the number of profile irregularities, $S_{\mathrm{mi}}$, considered (see Fig. 3(d)). The other roughness parameters studied, such as $R_{\mathrm{k}}$ and $R_{\mathrm{pk}}$, which are the core roughness depth and the reduced peak height, are well defined in standard DIN EN ISO 13565 [19].

\section{Presentation and analysis of results}

Fig. 4 presents two micrographs obtained by SEM examination, corresponding to cycle-dependent and time-dependent crack growth, respectively. The fracture surface presented in Fig. 4(a) is quite flat, indicating that propagation is mainly transgranular. Striations can be seen, signifying that propagation is produced by cyclic plastic deformation. The crack propagation observed in
Fig. 4(b) is intergranular, which gives a rough aspect to the fracture surface. The surface of the grains is irregular. Secondary cracking, perpendicular to the fracture surface, can also be observed. Fig. 5 gives a schematic representation of intergranular and transgranular crack growth. Figs. 4(a) and 4(b) show that the fracture surfaces are much rougher when propagation is intergranular, as expected.

Fig. 6 presents the roughness profiles obtained for different crack propagation modes. It can be seen that these modes significantly influence the crack path geometry, confirming the SEM observations. Roughness measurements were therefore performed on the fracture surfaces of specimens previously analyzed by SEM. Table 1 gives the results obtained for different roughness parameters. One of the objectives of this work was to find the parameter (or parameters) best suited to identifying a particular crack propagation mode. A parameter is adequate if

1. it presents stable mean values and low scatter of results for each crack propagation mode;

2. the values for different crack propagation modes are appreciably different.

The results in Table 1 show that almost all the parameters exhibit typical values for each of the crack propagation modes. These are stable within each mode and vary significantly from mode to mode.

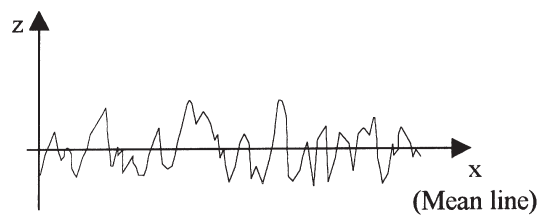

(a)

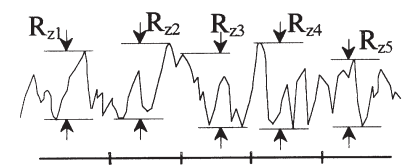

(c)

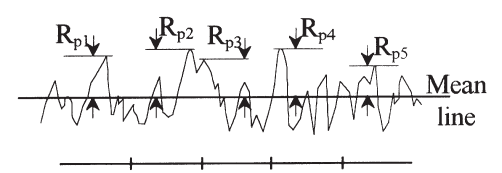

(b)

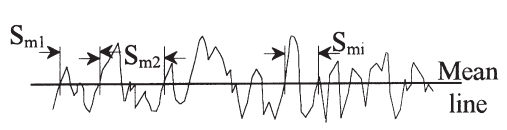

(d)

Fig. 3. Roughness parameters. 

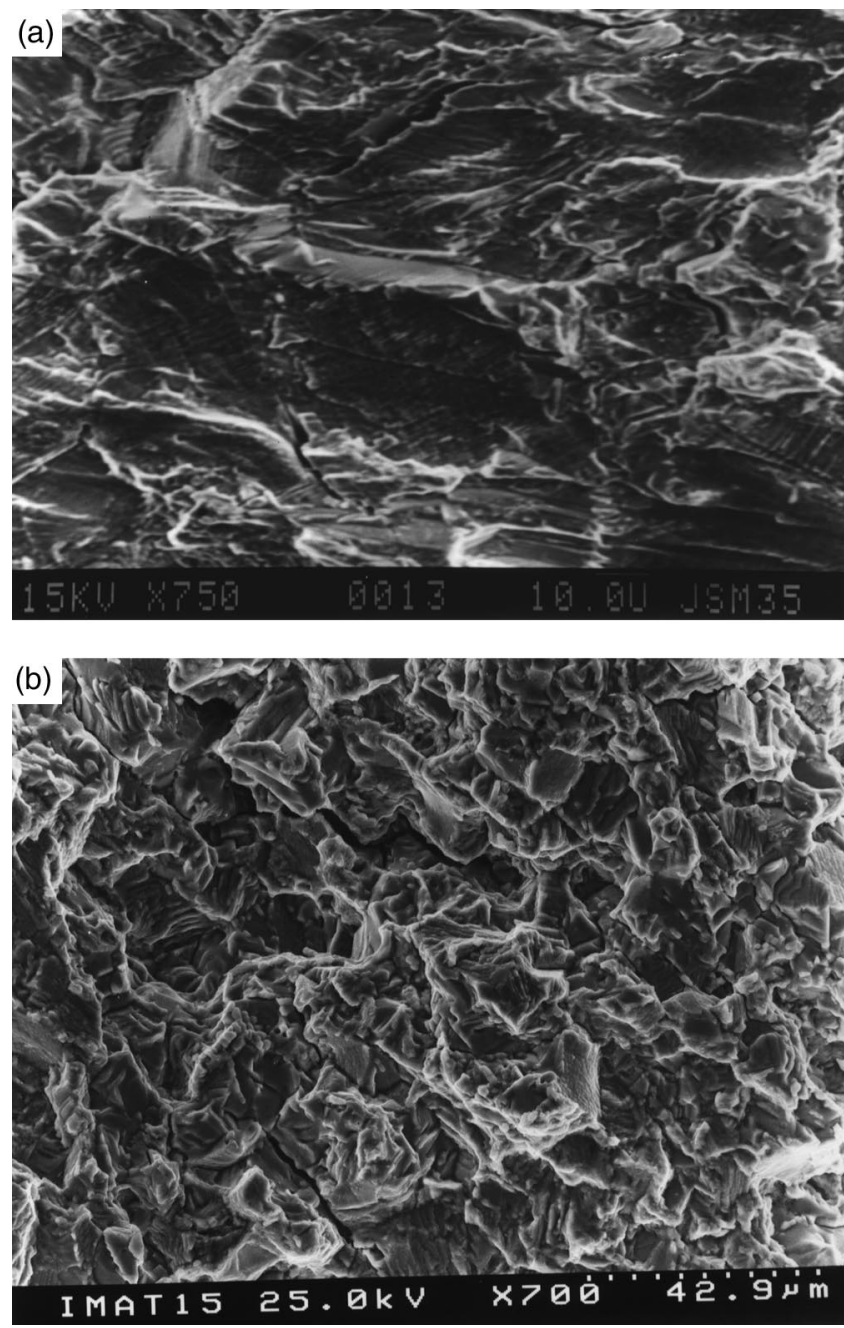

Fig. 4. Micrographs of fracture surface: (a) transgranular mode; (b) intergranular mode.

For comparison of the ability of the roughness parameters to characterize the fracture surface morphology, Fig. 7 shows the mean values and the scatter of the results obtained with the different parameters when analyzing fracture surfaces resulting from intergranular, transgranular and mixed propagation modes. The results obtained indicate that the parameters $R_{\mathrm{k}}, R_{\mathrm{pk}}$ and $S_{\mathrm{m}}$ cannot be used with confidence to identify the propagation mode, as they show superposition of the ranges obtained

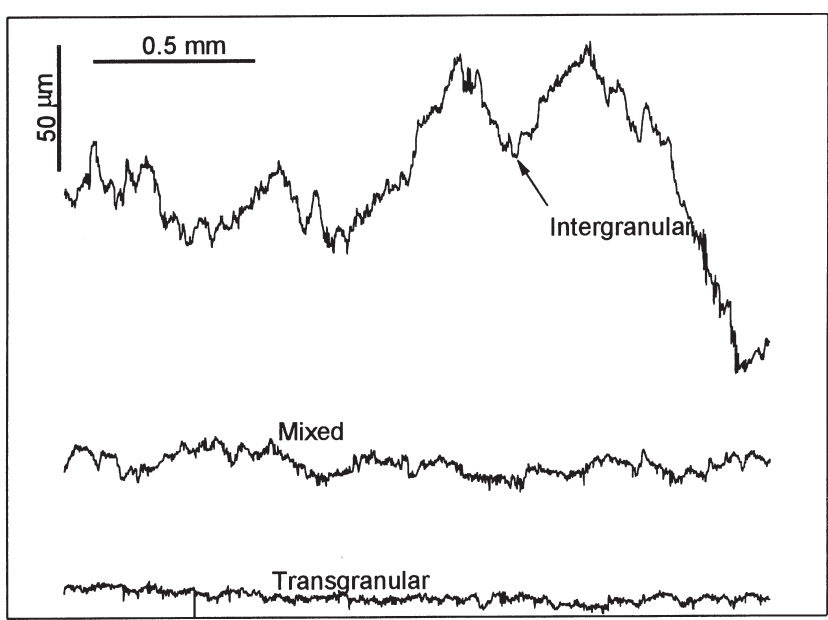

Fig. 6. Roughness profiles for the different crack propagation modes.

Table 1

Roughness of the crack surface

\begin{tabular}{lccrrrr}
\hline & $R_{\mathrm{a}}$ & \multicolumn{1}{c}{$R_{\mathrm{z}}$} & \multicolumn{1}{c}{$R_{\mathrm{pm}}$} & \multicolumn{1}{c}{$S_{\mathrm{m}}$} & \multicolumn{1}{c}{$R_{\mathrm{k}}$} & \multicolumn{1}{c}{$R_{\mathrm{pk}}$} \\
\hline Transgranular & 3.43 & 22.11 & 10.95 & 14.16 & 9.39 & 7.23 \\
& 2.43 & 17.19 & 6.29 & 6.72 & 6.95 & 1.63 \\
& 2.94 & 21.57 & 9.09 & 8.33 & 8.36 & 4.74 \\
Mean & 2.2 & 16.99 & 7.86 & 10.31 & 6.71 & 2.37 \\
Intergranular & $\mathbf{2 . 7 5}$ & $\mathbf{1 9 . 4 6}$ & $\mathbf{8 . 5 5}$ & $\mathbf{9 . 8 8}$ & $\mathbf{7 . 8 5}$ & $\mathbf{3 . 9 9}$ \\
& 71.61 & 58.37 & 28.61 & 48.76 & 37.23 & 10.67 \\
& 8.38 & 39.58 & 19.57 & 27.98 & 23.47 & 8.81 \\
& 6.89 & 48.39 & 23.08 & 32.97 & 28.04 & 6.79 \\
Mean & 10.54 & 38.94 & 22.16 & 21.74 & 17.67 & 9.29 \\
Mixed & $\mathbf{9 . 0 2}$ & $\mathbf{4 8 . 5 3}$ & $\mathbf{2 4 . 1 8}$ & $\mathbf{3 4 . 2 4}$ & $\mathbf{2 7 . 8 4}$ & $\mathbf{9 . 0 4}$ \\
& 6.06 & 33.90 & 16.17 & 29.44 & 18.74 & 5.02 \\
Mean & 3.56 & 21.83 & 10.65 & 16.34 & 11.09 & 3.54 \\
& 4.3 & 27.2 & 12.79 & 19.02 & 13.14 & 4.37 \\
& $\mathbf{4 . 6 4}$ & $\mathbf{2 7 . 4 7}$ & $\mathbf{1 3 . 2 0}$ & $\mathbf{2 1 . 6}$ & $\mathbf{1 4 . 3 2}$ & $\mathbf{4 . 3 1}$ \\
\hline
\end{tabular}

for different propagation modes. However, different values were obtained for the parameters $R_{\mathrm{a}}, R_{\mathrm{z}}$ or $R_{\mathrm{pm}}$ for the propagation modes analyzed, so the roughness measurement of the fracture surfaces can be used as a tool to identify the crack propagation mode in nickel base superalloys, if suitable parameters are used.

The simultaneous influence of the crack propagation mode on the amplitude of roughness, which is confirmed
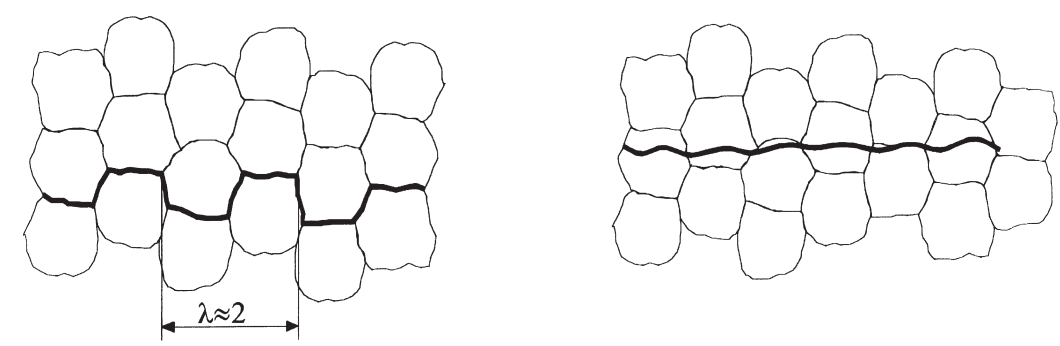

Fig. 5. Intergranular and transgranular crack propagation. 

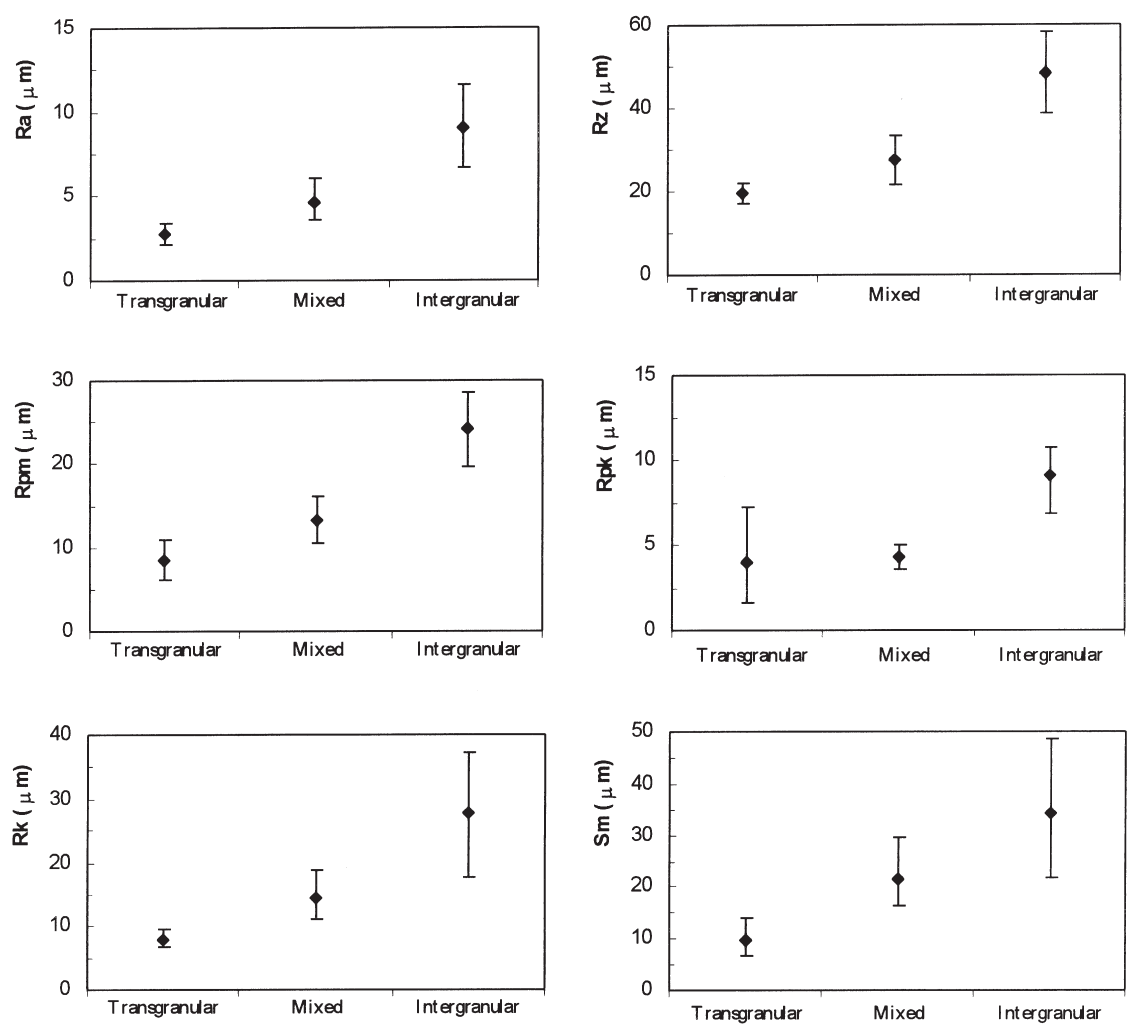

Fig. 7. Influence of crack propagation modes on roughness parameters.

by the change in parameters $R_{\mathrm{a}}, R_{\mathrm{z}}$ or $R_{\mathrm{pm}}$, and on the wavelength of profile irregularities (change of $S_{\mathrm{m}}$ ), led to the conclusion that the treatment in the frequency domain could be of great importance. Spectra of surface irregularities (amplitude versus wavelength) were thus produced using FFT (Fast Fourier Transform). Figs. 8(a) and 8(b) give some typical spectra obtained from fracture surfaces corresponding to intergranular and transgranular crack growth, respectively (previously identified by SEM). Comparison of these spectra shows that they vary significantly with crack propagation mode. In fact, an intergranular propagation produces rougher fracture surfaces, with the difference being more important for frequencies higher than $20 \mathrm{l} / \mathrm{mm}$, i.e. for wavelengths lower than $50 \mu \mathrm{m}$. Careful analysis of the spectra shows that intergranular crack growth produces an important increase in amplitude for frequencies in the range 20$50 \mathrm{l} / \mathrm{mm}$. As the grain size ranges from 10 to $20 \mu \mathrm{m}$ for this material, the frequency range corresponding to an intergranular propagation through the grain boundaries varies over the range $25-50 \mathrm{l} / \mathrm{mm}$ (Fig. 4). Therefore, the analysis of the spectrum in the frequency range corresponding to medium grain size can be used to decide whether the propagation is mainly intergranular or mainly transgranular.

In the light of the results obtained, the following strategy can be proposed to identify the crack propagation mode in a nickel base superalloy:
1. Find the spectrum in the frequency range to identify the crack propagation mode. A significant amplitude for the wavelength corresponding to grain size indicates that propagation is mainly intergranular, while the opposite indicates that it is mainly transgranular. The roughness values measured on the fracture surfaces can be used as typical values for intergranular and transgranular crack growth.

2. Identify the crack propagation mode for different loading or environmental conditions, comparing the roughness parameters with the characteristic values, The best roughness parameters for this study are $R_{\mathrm{a}}$, $R_{\mathrm{z}}$ or $R_{\mathrm{pm}}$.

\section{Identification of crack propagation mode in Inconel 718}

\subsection{Influence of loading frequency on crack propagation mode}

Roughness measurements were used to identify the crack propagation mode in Inconel 718. Fig. 9 gives the variation of roughness (quantified by $R_{\mathrm{pm}}$ ) with loading frequency $(f)$, for $R=0.5$ and $T=600^{\circ} \mathrm{C}$. More than one measurement was considered for each specimen. The heterogeneous character of a fracture surface can explain 

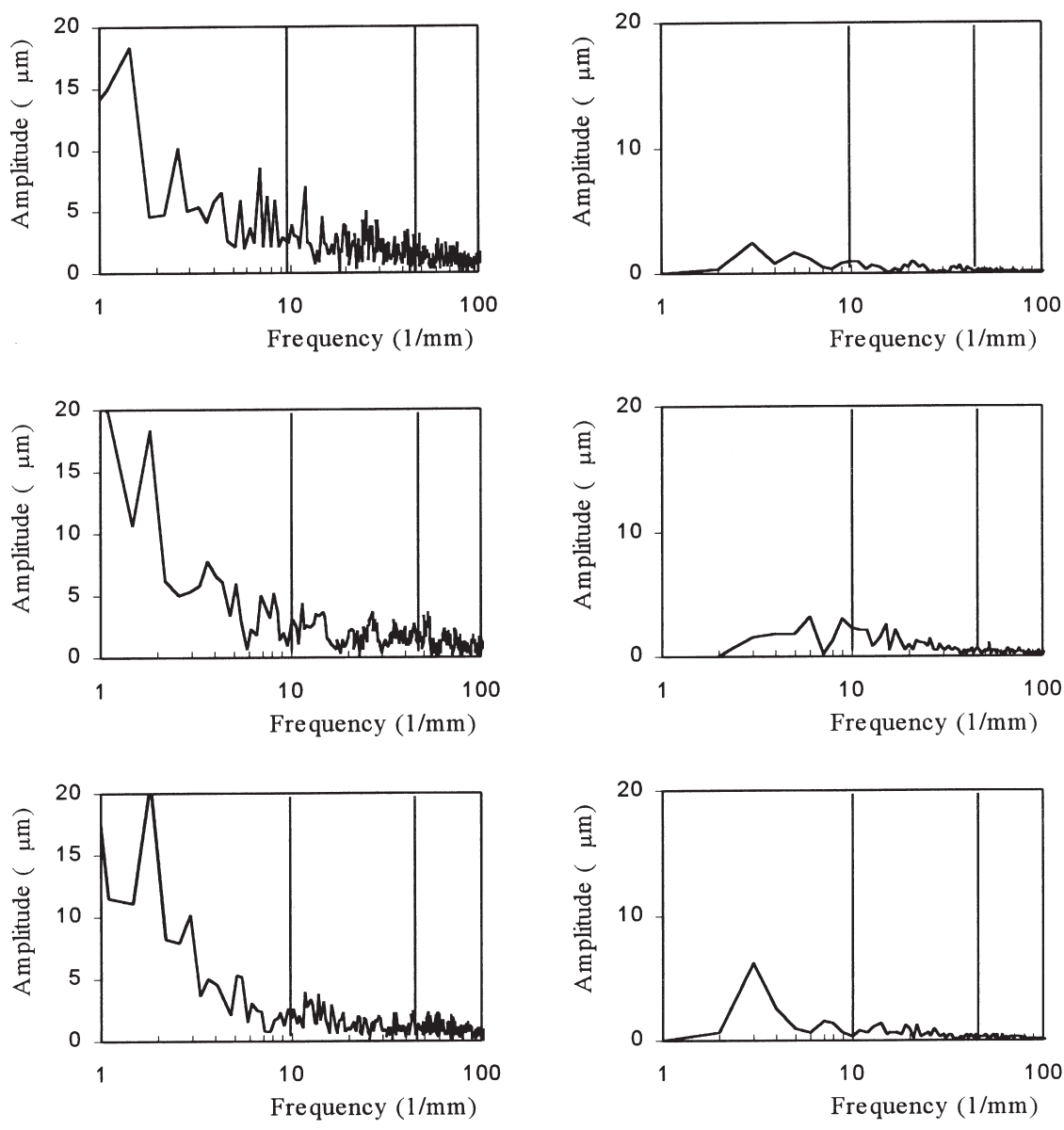

(a)

(b)

Fig. 8. Spectra of fracture surface roughness: (a) intergranular mode; (b) transgranular mode.

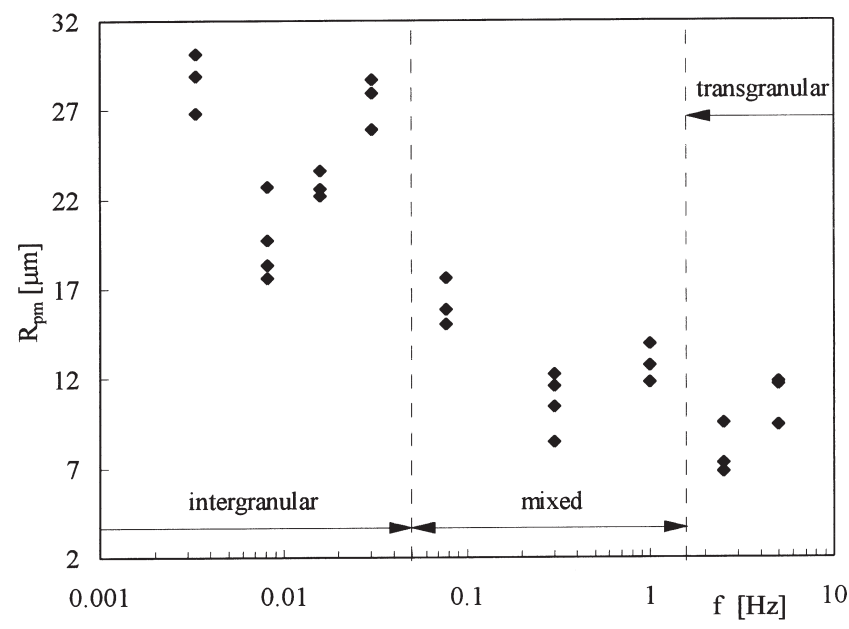

Fig. 9. Variation of fracture surface roughness with loading frequency.

the scatter of measurements taken on the same surface. Three regimes of crack propagation can be identified: cycle-dependent (lower values of $R_{\mathrm{pm}}$ ), time-dependent (higher values of $R_{\mathrm{pm}}$ ) and mixed. The transition fre- quencies, identified by the vertical lines in Fig. 9, are: from cycle-dependent to mixed crack growth $f_{\mathrm{cm}} \approx 1.6$ $\mathrm{Hz}$, and from mixed to time-dependent crack growth $f_{\mathrm{mt}} \approx 0.05 \mathrm{~Hz}$.

\subsection{Influence of stress state on crack propagation mode}

Fig. 10 presents roughness values for two test conditions (T1, T2). These values were obtained from profiles parallel to a free surface and at different distances $(x)$ from it. The interior roughness of specimen T1 (i.e. at a distance from the surface) indicates that crack propagation is intergranular, while the interior roughness of specimen T2 indicates that propagation is transgranular. This conclusion is based on the comparison with the values given in Fig. 9. The values obtained at the surface indicate that propagation is transgranular in both specimens. Therefore, the plane stress state inhibits timedependent crack propagation (intergranular). This can be explained by the reduced oxygen diffusion produced by the planar stress state. In fact, higher diffusion rates are associated with triaxial stress states. The near-surface 


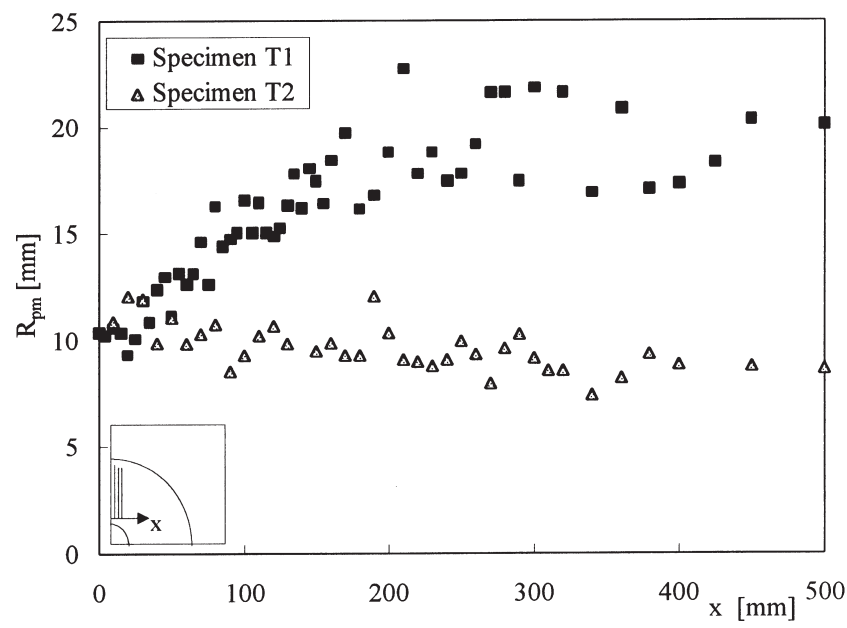

Fig. 10. Variation of fracture surface roughness with stress state (T1, $R=0.8, f=0.14 \mathrm{~Hz} ; \mathrm{T} 2, R=0.05, f=0.1 \mathrm{~Hz}$ ).

region extends for approximately $200 \mu \mathrm{m}$ for this loading and crack length.

These results may explain the crack shapes for the corner cracks. When the crack propagation mode is the same inside the specimen and near the surface, the crack adopts an almost quarter-circular shape because the fatigue crack growth rate (FCGR) is not greatly affected by stress state. However, when the crack propagation modes are different, a quarter-circular crack has a lower FCGR near the surface, and so a tunnelling effect is observed. This agrees with findings of Tong et al. [15] in Waspaloy at $650^{\circ} \mathrm{C}$. In fact, a greater tunnelling effect of the crack front (i.e. a higher influence of stress state) was observed when the interior crack growth was time-dependent.

\section{Conclusions}

1. Roughness measurements can be used to identify the fatigue crack propagation mode in nickel base superalloys at high temperature. Although roughness measurements can be used as an alternative to fractography, they are better used as a complement to this technique.

2. The parameters $R_{\mathrm{a}}, R_{\mathrm{z}}$ and $R_{\mathrm{pm}}$ are the most suitable ones for identifying the crack propagation mode.

3. Analysis of spectra in the frequency range showed that the profiles with wavelengths identical to the grain size are dominant when the propagation is intergranular.

4. Three crack propagation modes were identified in the frequency range for Inconel 718 tested at $T=600^{\circ} \mathrm{C}$ and $R=0.5$. The transition frequencies are: from cycledependent to mixed crack growth $f_{\mathrm{cm}} \approx 1.6 \mathrm{~Hz}$, and from mixed to time-dependent crack growth $f_{\mathrm{mt}} \approx 0.05 \mathrm{~Hz}$.
5. Stress state was found to have a strong influence on crack propagation mode. Near the free surfaces, the plane stress state promotes a change from time-dependent to cycle-dependent crack growth. This is explained by a reduction of oxygen diffusion induced by plane stress. The occurrence of tunnelling can be explained by the influence of the stress state.

\section{References}

[1] Thompson AW. Fractography and its role in fracture interpretation. Fatigue and Fracture of Engineering Materials and Structures 1996;19(11):1307-16.

[2] Ritchie RO, Thompson AW. On macroscopic and microscopic analysis for crack initiation and crack growth toughness in ductile alloys. Metallurgical Transactions A 1985;16A:232-48.

[3] Thompson AW, Ashby MF. Fracture surface micro-roughness. Scripta Metallurgica 1984;18:127-30.

[4] Casado JA, Polanco JA, Gutiérrez-Solana F, Carrascal I, Sétien J. Parametros criticos del comportamiento en fatiga de la poliamida 66 reforzada con fibra corta de vidrio. Anales de Mecanica de la Fractura 1999;16:228-34.

[5] Ravichandran KS. A theoretical model for roughness induced crack closure. International Journal of Fracture 1990;44:97-110.

[6] Hamberg K, Wasén J, Karlsson B. The influence of the topography of fracture surfaces on crack closure. In: Ritchie R, editor. Fatigue 87. Wanley: EMAS, 1987.

[7] Buhl H. Advanced aerospace materials. Materials Research and Engineering, Springer-Verlag, 1992.

[8] Pineau A. Defect assessment procedures in the creep range. In: Branco CM et al, eds. Proceedings: Mechanical behaviour of materials at high temperature. NATO/AS1 Series 1995;15:59-82.

[9] Solomon HD. Metallurgical Transactions 1973;4:341-7.

[10] Winstone MR, Nikbin KM, Webster A. Modes of failure under creep-fatigue loading of a nickel-based superalloy. Journal of Materials Science 1985;20:2471-6.

[11] Gayda J, Gabb TP, Miner RV. Fatigue crack propagation of nickel base superalloys at $650^{\circ} \mathrm{C}$. In: Solomon HD, editor. Proceedings: Low cycle fatigue, ASTM STP 942. Philadelphia: American Society for Testing and Materials, 1988:293-309.

[12] Weerasooriya T. Effect of frequency on fatigue crack growth rate of Inconel 718 at high temperature. In: Cruse TA, editor. Proceedings of the Nineteenth Symposium on Fracture Mechanics. ASTM STP 969. Philadelphia: American Society for Testing and Materials, 1988:907-23.

[13] Antunes FJV. Influence of frequency, stress ratio and stress state on fatigue crack growth in nickel base superalloys at elevated temperature. PhD thesis, Department of Mechanical and Manufacturing Engineering, University of Portsmouth, UK, 1999.

[14] Byrne J, Hall R, Grabowski L. Elevated temperature crack growth in a nickel base superalloy. In: Proceedings: Defects at high temperature, ESIS15. London: MEP Publications, 1993.

[15] Tong J, Byrne J. Effects of frequency on fatigue crack growth at elevated temperature. Fatigue and Fracture of Engineering Materials and Structures 1999;22(3):185-93.

[16] Sundararaman M, Mukhopadhyay P, Banerjee S. Some aspects of the precipitation of metastable intermetallic phases in Inconel 718. Metallurgical Transactions A 1992;23:2015-28.

[17] ISO 4287 Geometrical product specifications (GPS). Surface texture: Profile method-terms, definitions and surface texture parameters. 1997.

[18] ISO 4288 Geometrical product specifications (GPS). Surface tex- 
ture: Profile method—rules and procedures for assessment of surface texture. 1996.

[19] ISO 13565-2 Geometrical product specifications (GPS). Surface texture: Profile method-surfaces having stratified functional properties. Part 2: Height characterization using the linear material ratio curve. 1996. 